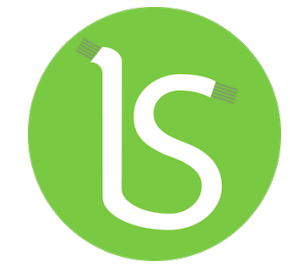

\title{
Red Local de Gestión del conocimiento y la innovación para el desarrollo local
}

\author{
Carlos Alberto Hernández Medina ${ }^{a}$ \\ Alexander Báez Hernándezb \\ Magdalys Alibet Carrasco Fuentesc
}

Resumen - Este estudio, desde un enfoque integrador, interviene en el debate académico internacional y nacional sobre el tema de la gestión del conocimiento para el desarrollo agropecuario local. Realiza una sistematización actualizada de los referentes teóricos representativos sobre desarrollo agropecuario local y gestión del conocimiento que justifica el papel del primero como factor condicionante, reconociendo la responsabilidad de los gobiernos municipales con sus entidades subordinadas que son los articuladores y actores principales de estos procesos, donde debe prevalecer lo comunitario como una de sus cualidades esenciales La metodología aplicada contribuyó a diagnosticar las condiciones expresadas en las potencialidades y los obstáculos más importantes existentes en el entorno agropecuario municipal, que el Gobierno local debe evaluar para implementar acciones de gestión del conocimiento en la conformación de la estrategia de desarrollo agropecuario local.

Palabras clave - Educación Superior, Desarrollo, Gestión del Conocimiento, Producción Agropecuaria, Localidad.

Abstract - This study, from an integrative approach, intervenes in international and national academic debate about knowledge management for local agricultural development. Performs an updated systematization of representative theoretical referents on local agricultural development and knowledge management that justifies the role of the former as a conditioning factor, recognizing the responsibility of municipal governments with their subordinate entities that are the articulators and main actors of these processes, where community should prevail as one of its essential qualities The methodology applied helped to diagnose the conditions expressed in the potentials and the most important obstacles existing in the municipal agricultural environment, which the local government must evaluate to implement knowledge management actions in the conformation of the strategy of local agricultural development.

Keywords - Higher Education, Development, Knowledge Management, Agricultural Production, Locality.

\author{
CÓMO CITAR \\ HOW TO CITE: \\ Hernández Medina, C. A., Báez \\ Hernández, A., \& Carrasco \\ Fuentes, M. A. (2022). Red \\ Local de Gestión del \\ conocimiento y la innovación \\ para el desarrollo local. \\ Interconectando Saberes, (13), \\ I I5- 140. \\ https://doi.org/ 10.25009/is.v0il 3 \\ .2649 \\ Recibido: 16 de noviembre de \\ 2019 \\ Aceptado: 22 de noviembre de \\ 2021 \\ Publicado: 31 de enero de 2022
}

\footnotetext{
${ }^{a}$ Centro Universitario Municipal Camajuaní, Cuba. E-mail: cahm862@uclv.edu.cu

b Universidad Central de Ecuador, Ecuador. E-mail: albaez@uce.edu.ec

c Centro Universitario Municipal Camajuaní, Cuba. E-mail: alibet7305@uclv.edu.cu
} 


\section{INTRODUCCIÓN}

En los países desarrollados se dedican grandes recursos para asegurar la apropiación y uso intensivo del conocimiento para acceder a mercados donde el valor agregado a los productos determina la supervivencia competitiva. Su objetivo es captar conocimiento relevante y capitalizarlo en sus productos, asegurando crear riqueza para grandes empresas monopolistas. Poseer conocimiento expresado en know how es determinante y el dinero pagado se asume como inversión estratégica que se realiza y justifica en la capacidad del conocimiento relevante para generar valor agregado. Así surgió la gestión del conocimiento, tema emergente de interés académico y profesional contemporáneo.

En la bibliografía predomina una orientación economicista sobre el conocimiento. Esa es una regularidad internacional porque la producción teórica sobre gestión del conocimiento procede de los países industrializados. En su mayoría está rigurosamente encaminada hacia la economía en detrimento de lo social. En América Latina la realidad no difiere mucho, aunque existen ejemplos muy interesantes en Argentina, Venezuela y Brasil. Esa regularidad impone, para su aplicación en Cuba, la necesidad de despojar a la gestión del conocimiento de la esencia del sistema de dominación donde se creó y adecuarla a las condiciones del país.

En Cuba, el Programa Ramal Gestión del Conocimiento para la Innovación y el Desarrollo (GUCID), fue un esfuerzo comprometido del Ministerio de Educación Superior para contribuir al desarrollo local. Surgió en 2006 por iniciativa de la Cátedra CTS+I de la Universidad de La Habana, abanderada de los estudios de desarrollo local en el país. De aquel Programa Ramal surgió la Red GUCID donde participan con sus proyectos gran parte de las universidades cubanas, centros de investigación y Centros Universitarios Municipales de varias provincias. Entre ellos se destacan los CUM Yaguajay, Remedios, Camajuaní, Placetas, Mayarí, El Salvador, La Palma y Jatibonico.

A partir de objetivos iniciales que posibilitan dirigir las acciones, cada actor involucrado en GUCID estudia y documenta su realidad local y adquiere conocimiento relevante sobre sus potencialidades para el desarrollo local. La idea inicial de esta investigación, que se inició en 2007, surgió a partir de dos proyectos iniciales en ese Programa (MES, 20I2a y MES, $2012 b$ ).

La municipalización de la Educación Superior y el proceso de transformar el modelo socioeconómico crearon oportunidades no aprovechadas con eficacia aún en contextos locales por resistencia de la práctica tradicional que obstaculiza desplegar la gestión del conocimiento para catalizar procesos de innovación (Schulze, 2003).

La capacidad del municipio para desarrollarse depende en lo fundamental de la disposición de los actores locales expresada en niveles de cohesión social y en cómo aplican productivamente el conocimiento que poseen o captan. Sin embargo, esos saberes diversificados pueden coexistir junto a los problemas sin lograr soluciones. Esos vínculos necesitan una concepción comunitaria para identificar, adquirir, desarrollar, difundir, utilizar y retener conocimiento presente en la vida social local o fuera de ella. (Garcés, 2013). Eso es posible si se fortalece una participación en la que mecanismos de deliberación eficaces y responsabilidad de los actores son elementos 
constitutivos de la capacidad de la sociedad local para ejecutar una política de desarrollo viable y consensuada. (Cravacuore, 2010).

El objetivo general de esta investigación fue construir un marco teórico sobre la gestión del conocimiento para el desarrollo agropecuario local.

\section{LA GESTIÓN DEL CONOCIMIENTO PARA EL DESARROLLO AGROPECUARIO LOCAL}

Los estudios teóricos y análisis de experiencias permitieron conceptualizar el desarrollo local como proceso de crecimiento económico y cambio estructural, liderado por la comunidad, con el Gobierno al frente, utilizando el potencial de desarrollo, que mejora el nivel de vida de la población, donde lo local se integra a lo económico al incluir todos los sectores y necesidades sociales $y$ hay sostenibilidad medioambiental. En la mayoría de los municipios cubanos, con fuerte componente agropecuario de su actividad socioeconómica, el desarrollo agropecuario local tiene el mayor peso en su estrategia de desarrollo.

El desarrollo agropecuario local es, entonces, aplicación de la ciencia y la técnica para resolver los problemas que afectan la producción integral de alimentos en el territorio. La solución de los problemas que se presentan en los procesos de producción agropecuaria local solo se puede lograr con la aplicación de la gestión del conocimiento para el desarrollo agropecuario local.

\section{DESARROLLO AGROPECUARIO LOCAL}

\section{Según Casanova (2009) el desarrollo} agropecuario debe lograr 3 objetivos esenciales: I. Económico: fortalece el tejido económico local, incrementa la productividad a través de mano de obra calificada, amplía el mercado e incrementa la renta per cápita, 2. Social: mejora de bienes y servicios básicos como educación o alimentación y aumenta el nivel de vida con incremento de ingresos y posibilidad de potenciar procesos de participación y cooperación en temas económicos y sociales y 3. Ambiental: gestión adecuada de los recursos naturales mediante formación, información y prevención creando conciencia sobre su uso racional.

Tres aspectos de carácter económico y social caracterizan el desarrollo: es integrado al incluir los sectores económicos y necesidades sociales, participativo porque atiende la opinión y logra participación activa de la población a la que implica y endógeno por el uso y aprovechamiento de los recursos locales.

El concepto de localidad es útil pues nos permite hacer interpretaciones de lo local a lo global y reconocer el derecho a las teorías, construcciones $y$ transformaciones de la realidad; es punto de encuentro entre territorio y desarrollo. El territorio es sujeto y el desarrollo proceso de construcción económica, social, política, cultural y medioambiental. Lo local representa el ámbito donde los agentes territoriales adquieren capacidad de fijar el rumbo, de construir el desarrollo.

Desarrollo local es, por tanto un proceso territorializado de maduración de relaciones sociales, aprendizaje colectivo para el cambio cultural y construcción política que se despliega en múltiples dimensiones, Es construido a partir de potencialidades $y$ capacidades locales de sus factores y agentes, generado y adquirido por actores locales que pasan de espectador a protagonista de su destino, Entrelaza procesos económicos, sociales, políticos, culturales y 
medioambientales y supera una visión sectorial y vertical de la economía.(Fajardo y Figueiras, 2009)

Su fin es el progreso permanente del territorio, localidad, comunidad e individuos que residen allí. Al vincularse estrechamente a un proceso de crecimiento económico requiere como condiciones: un proceso de autonomía para emprender un estilo propio de desarrollo y aplicar políticas autóctonas; capacidad de apropiarse del plusproducto para reinvertir en el proceso; actitud permanente de conciencia sobre protección ambiental y uso racional de los recursos naturales para incrementar el nivel de vida; identificación plena de la población con su territorio que le da sentido de pertenencia e identidad y se vincula a su historia, psicología, lengua, tradición y arraigo sociocultural al territorio, logrando verdadero sentido de pertenencia que desarrolla cohesión y posibilita motivar a cada individuo; por el significado social del proceso, el ingreso se debe repartir a la población con justicia y equidad, garantizando su participación en la toma de decisiones; el protagonismo entendido como liderazgo de los gestores del desarrollo local es indispensable y la coordinación entre agentes del desarrollo es condición necesaria para consolidar el desarrollo local. (Lloret y Méndez, 2005)

El desarrollo local, como estrategia territorial basada en aprovechar el potencial endógeno con adecuada inserción de impulsos y recursos estratégicos exógenos, tiene carácter pluridimensional e integrado y supone implantar un proceso sistemático y sostenible a largo plazo, de dinamizar el territorio y la sociedad local, mediante la participación protagonista y co-responsable de los actores socioeconómicos y políticos locales. Por eso la estrategia de desarrollo local se instrumenta a través de medidas de política de carácter multisectorial y sectorial, que actúan de manera sistemática sobre los factores de competitividad de cada territorio (Carmona y Vásquez, 2008).

Definir la estrategia de desarrollo agropecuario del territorio es una de las tareas más importantes del gobierno. El enfoque de desarrollo sostenible aconseja fortalecer la economía local aprovechando factores endógenos para generar riqueza y redistribuirla, enfrentar pobreza, exclusión social y desempleo y prevenir procesos de deterioro ambiental. (Díaz y Arroyo, 2006).

La conceptualización del desarrollo se ha enriquecido con diversas visiones hasta plantearse en su dimensión espacial dando lugar a conceptos como desarrollo territorial, regional, económico local, exógeno, endógeno, descentralizado y local. Tomando en cuenta los estudios sobre desarrollo local de Boisier, (200I), Limia (2004), López (2005), Guzón (2006), Núñez et al. (2008), Casalis (2007), Alonso y Riera (2010) y Garcés (20/3), esta investigación, por sus características, se suscribe a la definición que lo define como:

Proceso de superación de contradicciones desde una perspectiva comunitaria en los municipios. En él participan el pueblo, organismos y sectores de la economía en vínculo con las Asambleas Provinciales y Municipales del Poder Popular, mediante la planificación, organización, ejecución y control de los procesos inherentes al desarrollo, con prioridad en el fortalecimiento de la base productiva en cada territorio de manera integrada y articulada con los intereses nacionales (Rivero et al. 2008, pp. 12.) 
Desde esa posición se puede entender al desarrollo local como concepto holístico que integra todos los procesos que ocurren en el municipio. (Núñez, 20I I). Al apropiarse del concepto se asume lo comunitario como cualidad del desarrollo y se considera que para implementarlo se precisa la apropiación social de una concepción sobre comunidad ajena a la tradicional que la circunscribe al espacio físico y relaciones de vecindad. (Garcés, 2013). La noción de comunidad es asumida...

...desde dos perspectivas, una, como lugar donde lo espacial constituye el fundamento de adscripción para ubicar procesos en los que se manifiesta la particularidad que la hace distinguible frente a otras configuraciones sociales; o como relación social en que la simetría social del vínculo existente entre los sujetos permite señalar la esencialidad que la identifica y la lógica social de su devenir" “...es un grupo social donde transcurren procesos de cooperación y participación en torno a un proyecto colectivo. (Alonso et al., 2012. pp. 9.)

Esa definición se operacionaliza con más coherencia en procesos de desarrollo local si se tienen en cuenta los ejes transversales conciencia crítica, creatividad, participación, cooperación y proyecto. Es muy importante para construir redes sociales imprescindibles en procesos de desarrollo local y desarrolla la habilidad de encontrar los emergentes; donde está la verdadera contradicción oculta entre malestares o demandas menos consistentes.

La relación entre conocimiento y desarrollo local puede contribuir a transformar el municipio porque... ...el desarrollo depende cada vez más de factores de naturaleza intangible que actúan objetivamente como propiciadores y dependen de la capacidad de los actores locales para crear o mantener las condiciones e institucionalidad apropiadas para fomentar innovaciones. En esa perspectiva pueden asociarse elementos como nivel de capacitación de fuerza de trabajo, capacidad de asimilar nuevo know how y espíritu emprendedor...Estos pueden marcar la diferencia entre localidades y determinar en el éxito de las iniciativas de desarrollo local. (D’Angelo, 200I. pp.36.)

A partir de esa idea es clara la conclusión de que los esfuerzos para potenciar procesos de desarrollo local tienen que pasar por la gestión del conocimiento. La palanca del desarrollo local es el conocimiento. (Lage, 20I0).

La integración del conocimiento con las necesidades del desarrollo local puede materializarse si se hace corresponder el recurso estratégico principal, el capital humano, (Alburquerque, 2003) con los planes de desarrollo municipal para que las estrategias de gestión del conocimiento se correspondan prospectivamente con los escenarios sobre los que se construyó la visión del Gobierno y las organizaciones del territorio para que sean los intereses locales, debidamente representados, los que definan los contenidos del conocimiento a gestionar. Ese recurso estratégico principal que según Alburquerque (2003a) es mejor denominar patrimonio humano, más los conocimientos a gestionar, son elementos que están en las personas y sus capacidades; característica que le suma razón al valor de lo comunitario, de la posición asumida en del desarrollo local. 
Los procesos de desarrollo local serán más realizables si se basan en el conocimiento y la innovación, pero necesitan de participación calificada e interesada de todos los actores involucrados, cuyos intereses se afectan por el desarrollo, exige calificación, entrenamiento y habilitación permanentes, no sólo entusiasmo y deseos esporádicos e interventivos. (Limia, 2004). Limia (2004b) considera que la participación debe producirse en tres elementos primordiales: definición de prioridades a través de construcción conjunta del diagnóstico; definición de políticas para encauzar los resultados del diagnóstico, implementación de políticas a través de proyectos y control de resultados a corto, mediano y largo plazo.

Sin esa interacción proactiva, que podemos nombrar cooperación, no es viable desarrollar proyectos de desarrollo local comunitarios, que ayuden a articular estrategias, potenciales endógenos y oportunidades externas para superar obstáculos actuales, cuando la aplicación de los Lineamientos de la política económica y social del Partido y la Revolución (PCC, 20II) puede ser contribuir al éxito de procesos de desarrollo local. Alarcón (20I2) planteó que hay I4 lineamientos que directamente hablan de desarrollo local y 23 sobre tareas y acciones de desarrollo local. El $12 \%$ (3I3) está involucrados con el desarrollo local lo que prueba la prioridad que la alta dirección del país brinda al tema porque tomó conciencia de las enormes reservas de revelar el despliegue del desarrollo local y el gran aporte para la economía y la sociedad cubana. Reitera que si no se resuelven los problemas municipales no se resuelven los problemas globales. Esa oportunidad inédita abre al municipio una sólida perspectiva. Para ello es importante tener en cuenta antecedentes teóricos y prácticos que, de una manera u otra, afectan a los enfoques que, en diferentes etapas históricas, se han empleado en el desarrollo agropecuario local en América Latina.

\section{CRÍTICA A LOS ENFOQUES TRADICIONALES DEL DESARROLLO AGROPECUARIO}

Los viejos enfoques del desarrollo agropecuario son cada vez más irrelevantes frente a los cambios en las sociedades rurales actuales. Sus limitaciones son, según Chiriboga (2002), que: No ven la heterogeneidad que caracteriza las sociedades rurales, la pobreza y la pequeña agricultura. Desconocen el carácter multidimensional de la vida rural y tienden a enfrentarla con respuestas unívocas que no ven su complejidad fenomenológica, causas y manifestaciones. Se centran en la actividad agrícola y no incorporan el carácter multiactivo de la unidad familiar rural a pesar de la importancia del trabajo rural no agrícola, especialmente de las mujeres rurales en el mercado laboral.

No corrigen fallas de mercado frecuentes en el mundo rural que afectan más a pobres, pequeños y medianos productores limitándose a mitigar algunas con recursos de proyectos de desarrollo. Desvinculan las acciones orientadas a la transformación productiva de las que quieren reformar instituciones rurales y su dimensión institucional se reduce a organización y funciones del sector público, Ministerio de Agricultura y agencias de desarrollo. Fallan al articular políticas y acciones de desarrollo agropecuario con políticas de carácter macro. Tienen dificultad para asumir que el mercado tiene un peso decisivo en tendencias, oportunidades y restricciones que enfrentan los actores rurales. 
No consideran posible inducir a la agroindustria, servicios, empresas medianas y grandes, incluso las del sector urbano, a asumir el papel de difusoras de tecnología hacia determinados segmentos de la PyME rural (Schejtman, 1998). Carecen de capacidad para adecuar propuestas estratégicas o políticas gestadas centralmente a potencialidades y restricciones locales $\mathrm{o}$, a la inversa; no incorporan desde el inicio estrategias para replicar experiencias exitosas, ni ven el efecto que un desarrollo del núcleo urbano tendría en la mejora de la productividad rural y las condiciones rurales de vida $y$ trabajo. (Dirven, 1998).

La insatisfacción con los enfoques tradicionales dio lugar a fórmulas estratégicas para reenfocar el desarrollo agropecuario que avanzan hacia una propuesta de enfoque territorial. Los cambios en los condicionantes externos del desarrollo rural y la insatisfacción con respuestas tradicionales a la pobreza condujeron a una convergencia en las propuestas de desarrollo rural para América Latina. (OEI, 20I2).

El Fondo Internacional de Desarrollo Agrícola (FIDA, 2002), planteó desarrollar pequeñas poblaciones, ciudades de tamaño medio y corredores económicos, creando un entorno propicio para el desarrollo rural, mejorar el bienestar de la población rural, fortalecer la institucionalidad local, crear oportunidades de empleo, desarrollar industria, servicios y vínculos agriculturaindustria-servicios. EI BID adoptó enfoques de desarrollo territorial multisectorial en en su Asamblea Anual de Gobernadores, donde enfatiza el carácter multisectorial, territorial y descentralizado que deben tener las estrategias de desarrollo rural y lucha contra la pobreza. (BID, 2000). El Banco Mundial (World Bank, 2002), en su estrategia para superar la pobreza rural en América Latina y el Caribe, quiso impulsar un enfoque de espacio rural más allá de la visión sectorial agrícola y fortalecer la capacidad de absorción de los núcleos urbanos intermedios en un contexto de creciente interacción e integración rural-urbana, promoviendo una nueva institucionalidad sectorial que asegure gobernabilidad.

La FAO (2004) propuso un enfoque territorial del desarrollo agropecuario para ir de pequeño productor a familia rural ampliada, de empleo rural a multi-empleo, de política agrícola genérica a políticas diferenciadas acordes con tipos de unidad familiar, de producción agrícola a encadenamientos con agroindustria y servicios y de antítesis mercado-estado a construir instituciones mediadoras entre sociedad civil, estado y mercado.

Algunas experiencias regionales muestran preocupación por responder mejor a los desafíos que plantean la pobreza y el desarrollo agropecuario dando lugar a reformular estrategias rurales $y$ a medidas legislativas para cambiar los términos en que funcionan las economías locales en el ámbito rural. Brasil formuló el plan nacional de desarrollo agropecuario sustentable para implementar contratos territoriales de desarrollo (Veiga, 200I). México dictó la ley de desarrollo agropecuario sustentable, promoviendo programas a nivel municipal y regional a través de distritos de desarrollo agropecuario y formuló la estrategia nacional de atención a 250 microrregiones y creó centros estratégicos comunitarios como punto detonador de desarrollo de espacios predeterminados (Ruiz, 2002).

Bolivia dictó la ley de participación popular y ley de descentralización, induce un masivo proceso de planificación municipal participativa que involucró al $37 \%$ de la población rural y a casi dos tercios de los bolivianos pobres. Colombia, con el fondo de desarrollo 
agropecuario integrado, transfirió a los gobiernos municipales la posibilidad de promover y dirigir el desarrollo agropecuario, en lugar del poder central. Ecuador, con financiamiento del Banco Mundial, inició el proyecto de desarrollo local sostenible (PROLOCAL, 2002), para su plan de desarrollo en 150 municipios.

\section{GESTIÓN DEL CONOCIMIENTO}

Sobre gestión del conocimiento existe bibliografía con pluralidad de orientaciones, enfoques e intenciones porque su empleo como herramienta depende de las necesidades y el contexto. Entre los autores que se destacan en el tema se encuentran, Nonaka y Takeuchi (1999), Bueno (2003), Segarra (2006), Bañegil y Sanguino (2008), Faloh, 2009, García (20I0), Bárcenas (20I2), Prada (20I2) e Iñiguez (20I2). En Cuba los trabajos realizados sobre gestión del conocimiento valoran su importancia para el desarrollo del país, desde que fue introducida por CITMA (2002) sobre todo con un enfoque empresarial.

Estudios posteriores han demostrado que la gestión del conocimiento como proceso social es aplicable en otros contextos. Ha ido ganando fuerza su empleo en los procesos de desarrollo local cubanos donde se destacan las investigaciones de Lage (2006), Becerra (2008), Correa (2009), García (2010), Boffill (20I0), Núñez (20I0), Pereira (20II), Reyes (20II), Garcés (20I3), Hernández (20I5), Hernández y Cárdenas (2015), Hernández y Carrasco (20I5), Carrasco et al. (20I5), Hernández et al. (20I5) y García et al. (2016).

Existen variadas definiciones que conceptualizan el término y estas responden a los contextos de aplicación para los que fueron creadas. En Cuba, para mostrar el rol de la Educación Superior en la gestión del conocimiento para el desarrollo agropecuario local se asume como pertinente el concepto de Garcés (2013) que define la gestión del conocimiento como:

... el conjunto de acciones, procesos, vínculos intersubjetivos que permiten que el patrimonio intelectual de una entidad o lugar como suma de capacidades y valores individuales, colectivos y locales se incremente de manera significativa en correspondencia con los recursos existentes y las ideas estratégicas que orientan sus procesos de desarrollo y está dirigida a identificar, adquirir, desarrollar, difundir, utilizar y retener los conocimientos relevantes... (p. 58)

Se suscribe ese concepto porque sus dimensiones están muy cercanas a las necesidades de la creación de un modelo teórico metodológico que las articule en la gestión del desarrollo agropecuario en un municipio cubano.

\section{Gestión del conocimiento para el desarrollo agropecuario local en el mundo y Latinoamérica.}

Las teorías sobre desarrollo agropecuario y papel de pequeños productores en la producción agrícola han tenido cambios importantes desde el inicio de la década de los 90 del siglo XX. (Arocena y Sutz, 2006).

\section{La visión tradicional}

Sostenía que el campesino no puede integrarse a la economía moderna por sus valores de tradicionalidad y su economía casi independiente de la nacional que lo explota con restricciones para mantenerlo pobre. Entre 1970 y 1980, teóricos campesinistas planteaban que el campesino es eficiente productor y la estrategia de desarrollo agropecuario debía basarse en pequeñas propiedades. Sus programas 
de desarrollo agropecuario buscaban los objetivos de: incrementar producción con mecanismos de modernización tecnológica o colonizar áreas no adecuadas, generar sistemas de subsidio estatal a la producción y estructuras de comercialización paralelas y alternativas al mercado formal. La aplicación de esa visión tuvo pocos logros y provocó la generación de condiciones de pobreza profunda y degradación ambiental. Como consecuencia del desastre se buscó un nuevo modelo de desarrollo, caracterizado por buscar sostenibilidad. (FAO, 2004)

\section{El desarrollo agropecuario sostenible}

Como modelo se basa en que los pequeños productores tienen limitaciones para llevar adelante un proceso productivo moderno y conseguir éxito en las actuales condiciones de mercado competitivo e internacionalización de la economía. Al promover estrategias de desarrollo agropecuario sostenible se debe entender que esto es un cambio sustantivo en la forma que los actores se relacionan con la sociedad global. Por eso, un objetivo primordial de cada proyecto es generar condiciones para aumentar la producción y productividad agrícola que implica buscar métodos adecuados de promoción de cambios en las prácticas productivas y de comercialización. (OEI, 20I2)

\section{La gestión del conocimiento como núcleo del desarrollo agropecuario sostenible}

Promueve el cambio tecnológico y cultural y el cambio de pautas de comportamiento cotidiano del productor respecto a la tecnología, prácticas comerciales y formas de relacionarse entre ellos y con el entorno social y económico. (BID, 2000), fin muy difícil de cumplir pues pocos actores tienen visión clara de su medio social y económico. El cambio cultural implica alta responsabilidad del capacitador, la Educación
Superior, pues cambios muy profundos pueden traer consecuencias negativas a la sociedad en que se impulsa desarrollo.

De todo eso el autor concluye que la Educación Superior puede contribuir a la preparación para la gestión del conocimiento y convertirse en importante componente del desarrollo agropecuario local. En los procesos de capacitación y proyección estratégica, la Educación Superior puede ayudar a que los actores locales comprendan los fines y métodos adecuados para cumplir los objetivos de desarrollo agropecuario sostenible. La experiencia señala que, si no se logra consolidar un proceso de cambio cultural adecuado a los propósitos iniciales, las acciones de desarrollo no son sostenibles.

La garantía de un proceso de cambio productivo sostenible es preparar los actores en los objetivos del proyecto desde el inicio y durante todo su transcurso. La capacitación debe provocar cambios de mentalidad sobre los objetivos del desarrollo agropecuario con un nuevo enfoque metodológico y de relación entre actores para adoptar la visión participativa del desarrollo. Los proyectos productivos agropecuarios, entonces, deben adaptarse a las restricciones técnicas de los productores, considerando sus historias productivas y niveles educativos. (Hernández, 2015)

\section{Enfoque participativo}

La gestión del conocimiento como instrumento para el desarrollo agropecuario no puede ser llevada a cabo de forma mecánica sino en función de los objetivos de una estrategia. Se debe avanzar paso a paso, que los actores se apropien la tecnología y la puedan transmitir a otros como experiencia vivida. Esto, que parece tan simple, no era considerado en el pasado por enfoques intervencionistas que pensaban que el técnico era el 
maestro, único dueño de la verdad y los campesinos, alumnos que acataban. El fundamento del nuevo enfoque de desarrollo agropecuario sostenible, basado en participar en planificar y ejecutar los proyectos de desarrollo, asegura contar con la experiencia de los actores y el trabajo comunitario creando estrategias consensuadas para solucionar los problemas. (Veiga, 200I).

El desarrollo agropecuario sostenible debe seguir criterios generados en la experiencia comunitaria: comenzar con iniciativas modestas para que el aprendizaje y los procesos de cambio no generen cambios traumáticos en la estructura de producción y la sociedad local; incluir la participación en los beneficiarios en cada etapa del proceso; comenzar con una adecuada información técnica de producción y medio ambiente complementada con el punto de vista de los actores; hacer un diagnóstico verdadero sobre el medio ambiente; incorporar un plan de capacitación de técnicos, beneficiarios, familias y comunidad; dar prioridad a diversificar e integrar cultivos y actividades forestales; reducir el uso de agroquímicos rotando cultivos, con manejo integrado de plagas y uso de abonos orgánicos; plantar árboles o conservar bosques para sombra, leña y proteger laderas y ríos; beneficiar la comunidad sin exacerbar conflictos y diseñar actividades de seguimiento y evaluación continua del proyecto.

\section{GESTIÓN DEL CONOCIMIENTO Y DESARROLLO AGROPECUARIO}

Durante la implementación de la gestión del conocimiento en la sociedad cubana se debe divulgar y crear cultura sobre ella en el ambiente local, aplicar técnicas de gestión de información interna y externa e identificar procesos y acciones que propicien desarrollarla, aprovechar capacidades intelectuales, desarrollar capacidades, creatividad e innovación y crear nuevo conocimiento para enfrentar los desafíos del futuro. Para que el conocimiento se convierta en ventaja hay que captarlo, crearlo, distribuirlo, almacenarlo, compartirlo y usarlo; convertirlo en negocio con adecuada administración y gestión. (Garcés, 20/3).

Hay que desarrollar el aprendizaje basado en identificar y solucionar problemas, acelerar procesos de aprendizaje formal, tomar el conocimiento necesario para solucionar los problemas, formar equipos multidisciplinarios, buscar liderazgo en el aprendizaje organizacional, integrar recursos humanos y tecnológicos con concepto de mercadotecnia e identificar valores compartidos, conceptualizarlos e identificar cuáles son parte de nuestra cultura organizacional y es necesario fomentar para aplicación exitosa de gestión del conocimiento. (Rodríguez, 2005)

\section{LA CULTURA, EJE TRANSVERSAL EN LA GESTIÓN DEL CONOCIMIENTO PARA EL DESARROLLO} LOCAL

Según Garcés (2013) para incentivar el desarrollo de un municipio con coherencia, debemos afianzar el sentido de pertenencia hacia los elementos de identidad, dedicando a la cultura atención especial como elemento fundente y coincide con criterios de Limia (2004), Alburquerque (2007), Aguilera y Bao (2008), Garcés (2008), Martínez (2009), Reyes (20I I), Lage (20II), Leal (20II), Pérez (20II) y Alonso et al. (20I2). Toda acción de desarrollo debe ser sensible a los valores de la cultura (Carranza, 2002) y la actividad agropecuaria es esencialmente cultural, pero esto no se ve en el municipio si patrones estrechos al tratar el tema limitan lo cultural a lo artístico y literario. La cultura es 
concepto cosmovisivo que incluye toda la actividad humana $y$ no es posible materializarla sin la reproducción constante de las condiciones materiales de vida.

Cada territorio tiene patrones culturales propios, dentro de los cuales la forma de actuar en la producción agropecuaria y la vida rural son componente esencial. Olvidar la cultura productiva local puede promover producciones y comportamientos ajenos a necesidades y tradiciones locales, con consecuencias de una desvalorización gradual de la estrecha relación entre población y valores patrimoniales tangibles e intangibles que representan su identidad. En América Latina esta idea no siempre ha sido bien comprendida; por ejemplo, algunas experiencias de desarrollo local en Argentina fracasaron por no tener en cuenta que la clave son los actores locales del lugar; que pueden motorizar un proceso verdadero de desarrollo local. No es problema de generar ideas, deben ser ideas que se correspondan con la identidad local; con lo que se sabe en relación con las expectativas de la sociedad. Si no tiene que ver con la identidad local, la mejor idea se puede frustrar. (Arroyo, 2002)

Esta investigación pretende ratificar desde una posición dialéctica que es necesario tener en cuenta que el sujeto aprehende la realidad desde y a través de su cultura. (Aguilera y Bao, 2008). Si se deforma el legado cultural agropecuario los actores implicados construirán una realidad ajena. El papel de la cultura es sustancial en la calidad de vida y mejoramiento de la condición humana. (Prieto, 20I0). Se considera que las formas de producción agropecuaria local son parte del patrimonio sociocultural del municipio, deben aceptarse con responsabilidad y se debe dialogar con nuevas formas de hacer que permitan resolver problemas emergentes sin perder nuestro patrimonio ancestral. Esto dará lugar a procesos de innovación y adecuación socio-técnica que permitan el diálogo de saberes y la apropiación social de conocimientos relevantes.

Articular lo local y lo comunitario, la identidad, como fenómeno principalmente sociocultural, (Martínez, 2009) desempeña un rol fundamental. Ello complementa la concepción de la cultura como principal fuerza que liga los elementos del mundo social, media en la interacción entre actores e integra personalidad y actores sociales (Ritzer, 2007). Aunque Parsons, citado por Ritzer (2007) absolutiza la función causal de la cultura, vale para establecer el valor de lo sociocultural en el desarrollo local.

Esto motiva arraigo al municipio, sus valores y tradiciones autóctonas, combatidas por la globalización neoliberal (Bordieu, 20II) con concepciones erróneas sobre la importancia de lo local y su relación con lo universal que, instauradas en la praxis cultural de los actores puede debilitarlos porque la historia sólo es fuente viva si no se deja morir. Lo histórico no llega a la nueva generación como información genética, es parte del legado (Garcés, 2008), que se transmite en el diálogo intergeneracional.

Es vital fortalecer, a través de la gestión del conocimiento, la conciencia crítica como vía de apropiación creativa de lo cultural como representación social y sentido de pertenencia $y$, como valor compartido, que soporta lo comunitario como elemento aglutinador en la sociedad. La apropiación social del conocimiento de valores patrimoniales locales tangibles e intangibles debe ser integral y coherente para fortalecer responsabilidad social y sentido de pertenencia. Valorizar el conocimiento tradicional como parte del patrimonio es elemento relevante de identidad 
local y está presente, de forma tácita, en lo que la gente sabe y socializa en el diálogo intercultural en contextos locales (Garcés, 2013).

El autor considera que la apropiación crítica del conocimiento gestionado para la solución de problemas locales enriquece y fortalece la tradición productiva. Esto se debe a que en el proceso de capacitación para conocer $y$ adecuar la tecnología pertinente que se introduce los actores locales la hacen suya $y$ la incorporan a su praxis productiva porque la han adecuado a sus tradiciones. También asume la importancia de la transversalidad de la cultura en los procesos de desarrollo agropecuario local porque permite que los saberes de los actores sociales se expresen e intercambien de manera cotidiana.

\section{VALOR DE LAS REDES SOCIALES EN LA GESTIÓN DEL CONOCIMIENTO PARA EL DESARROLLO LOCAL}

El desarrollo agropecuario local es, en los municipios con fuerte componente económico en producción agropecuaria, un proceso que posibilita la vertebración social, económica e institucional. Por eso, como fin inmediato de la gestión municipal, el Gobierno y las instituciones locales debe articular y fortalecer los vínculos entre productores y gestar redes para desarrollar sinergias imprescindibles. Estas vinculan a los actores locales y son legítimas si se basan en valores socioculturales compartidos entre sus miembros. Entonces pueden contribuir a solucionar problemas de interés social.

Una de las bases analíticas que sustenta la idea de las redes de conocimiento es el planteamiento de Sábato y Botana (1975) sobre la necesidad de integrar los tres vértices del triángulo que permitiría el desarrollo de la región: las instituciones de investigación, instituciones de producción e instancias de apoyo gubernamental. De ahí parte el enfoque de los sistemas de innovación y el de los sistemas regionales y nacionales de innovación.

Entre los modelos de gestión del conocimiento se destaca que los modelos Sistema Nacional de Innovación, Modo 2 de producción de conocimiento y Modelo de Triple Hélice Universidad-EmpresaGobierno aportan ideas y conceptos de valor para trabajar la gestión del conocimiento para el desarrollo agropecuario local. Buscar sus limitaciones y aportes fundamentales permitió prever claramente el rumbo y prever la potencialidad integradora de la Educación Superior asentada en el territorio.

Construir procesos interactivos, conformar alianzas entre actores y el aprendizaje cotidiano en formación de redes son rasgos de la ciencia, la tecnología y la innovación actual. Esos procesos fueron identificados en la literatura hace mucho tiempo bajo el concepto de vinculación, enfatizándose la vinculación universidad-empresa. Sin embargo, se ha documentado en muchos estudios que el proceso de gestión del conocimiento implica participar un conjunto amplio de actores. (Casas, 2015)

Aguilar y Ander-Egg (2006) consideran que los actores sociales que interactúan en el desarrollo local se clasifican en: actores del sector público: miembros del gobierno local y las instituciones del Estado con el objetivo de llevar a cabo programas en función de políticas nacionales o locales de desarrollo, actores del sector privado: centrados en desarrollar una actividad productiva con fines de lucro y relacionados con organizaciones o individuos en función de esta actividad, actores de la economía social: organizaciones sociales que 
representan intereses de la ciudadanía y se relacionan con actores del sector público y privado en función de necesidades e intereses sociales específicos y actores del mundo académico: pertenecen a entidades científicas, artísticas, universitarias y educacionales y por su trayectoria, se convierten en actores claves para construir confianza validando información o asesorando decisiones. El autor considera que el actor más importante es el productor agropecuario y el gobierno local, como nodo principal de las redes para el desarrollo municipal, debe articular la actividad de los demás sectores sociales del territorio a tono con políticas e ideas estratégicas para mejorar la producción de alimentos.

Los municipios cubanos son actores importantes del desarrollo agropecuario, instituciones como el Centro Universitario Municipal, Consejos Populares, Delegación Municipal del Ministerio de Ciencia, Tecnología y Medio Ambiente (CITMA), Consejo Técnico Asesor y Sistema de Ciencia e Innovación, el Ministerio de Educación, con su red escolar y sistema de superación, Delegación Municipal del Ministerio de la Agricultura (MINAGRI), Unidades Básicas de Producción Cooperativa (UBPC), Cooperativas de Producción Agropecuaria (CPA), Cooperativas de Créditos y Servicios (CCS) y formas productivas como el Sistema de Agricultura Urbana y Suburbana, Asociación Nacional de Innovadores y Racionalizadores, Brigadas Técnicas Juveniles, Joven Club de Computación, asociaciones de técnicos agrónomos, pecuarios, azucareros y forestales, juristas, pedagogos, economistas, y contadores, Ministerio de Salud Pública, organizaciones políticas y de masas y trabajadores por cuenta propia.
Esos actores poseen acceso a redes nacionales como el Centro Universitario Municipal, Educación, Salud Pública y los Joven Club, que pueden conectarse a internet y el resto poseen acceso a redes nacionales, correo electrónico e intranet. Esa posibilidad tecnológica incrementa la potencialidad local para acceder a conocimiento relevante para el desarrollo local que puede estar fuera del municipio. En el municipio hay personas que, por su papel social, habilidades y conocimientos son importantes actores del desarrollo agropecuario que se articulan a redes y forjan vínculos. Las redes pueden aumentar sus flujos si se potencian las interacciones y el Gobierno local tiene en cuenta el enorme valor de estas interacciones y las incentiva en provecho integral del municipio.

Según Garcés (2013) la red del conocimiento es una estructura de desarrollo de sinergias, donde se socializan y reorientan dinámicamente los distintos saberes con el objetivo de resolver problemas sociales. Ayuda a articular las potencialidades del entorno territorial con la gestión municipal como dimensiones del desarrollo local. No se identifica la red como estructura basada en soportes electrónicos sino como sistema de relaciones interpersonales a partir de valores compartidos que propician una formación ciudadana amplia de los actores y aumenta la cohesión social.

El papel de los actores en la red se realiza en identificar y explotar lo que se sabe, saber quién tiene conocimiento relevante y establecer y profundizar la relación para adquirir esos conocimientos. Boffill (2010) plantea que los procesos de desarrollo local deben apoyarse en redes de actores y uso participativo de información, concediendo relevancia a la capacitación sistemática de actores y desarrollar capacidades innovadoras de resolver problemas en la comunidad, 
posible porque insertarse en redes sociales eleva ritmo de aprendizaje y apropiación social de conocimiento. La red permite la relación sinérgica entre conocimiento relevante $y$ actores $y$ es una estructura $\sin$ ordenamiento previo formada por personas $y$ organizaciones interesadas, desde diversas aristas, en el desarrollo (Garcés, 20I3). Es conjunto de saberes unido a la idea de la gestión, aporta reducción de grados de incertidumbre del desconocimiento y potencia ejercicio crítico de instancias socializadoras de la sociedad a través de la apropiación activa de la realidad. (Arés, 2003).

Son repositorio vivo y dinámico de valores y saberes prácticos y teóricos. La red tiene la ventaja de la flexibilidad, adaptación rápida a la demanda. En ellas ocurren dos procesos medulares: diálogo de saberes y gestación de lo comunitario como frutos de vínculos simétricos en torno a ideas o proyectos. Según Subirats (2005) los problemas actuales requieren abordaje desde la proximidad para responder mejor a situaciones específicas. Los actores locales conocen mejor sus necesidades y recursos y aportan su proximidad geográfica y cultural, facilitan todo tipo de interacción y crean condiciones para consolidar la red como espacio para detectar problemas locales que necesiten conocimiento y cooperación para resolverlos.

La red actúa en el espacio local, pero el tejido que logra supera esos límites. Establece lazos con actores importantes fuera del municipio y propicia procesos de innovación. La red local es garantía de que la sabiduría y la praxis individual o tácita de las personas, insertada en las ventajas que brinda la interacción comunitaria en el espacio local, se convierta, a través de la cooperación, en patrimonio social local. En ella la experiencia y el conocimiento se comparten, concretan y arraigan en saberes individuales y colectivos. (Leff, 2006). La interacción entre actores en redes del conocimiento es, según Ferreira (2009), fundamental para las estrategias de desarrollo local. Permiten construir una base de conocimiento y a través de ellas puede facilitarse la apropiación de tecnologías y promoverse, entre los actores implicados, el desarrollo de competencias necesarias para el municipio, asumiendo la noción de competencias como síntesis, nueva cualidad, que resulta de la interacción integrativa de diversas configuraciones, entre ellas: conocimientos, habilidades, valores, profesión, sociedad. (Aguilera y Bao, 2008).

La red, como forma integrada de interacción social, es capaz de fomentar procesos de comunicación eficientes, lograr diagnósticos efectivos y diseñar acciones eficientes para identificar, adquirir, desarrollar, difundir y utilizar conocimiento. Incrementa liderazgo del Gobierno y la cooperación entre los actores y la sociedad para desplegar de manera sostenible iniciativas de desarrollo local. Potencia en los actores capacidades de aprendizaje, estimula la gestación de lo comunitario como cualidad intrínseca que medie las interacciones sociales e incentiva innovación, apropiación social del conocimiento y diálogo de saberes fortaleciendo la identidad local y cohesión social. Su estructura horizontal permite plantear todas las posibles soluciones para facilitar el proceso de toma de decisiones. (Albornoz y Alfaraz, 2006).

El autor considera que el trabajo en red, tal como plantea en la hipótesis de investigación, puede fortalecerse con la aplicación de un modelo de gestión del conocimiento para contribuir al desarrollo agropecuario del municipio, si se tienen en cuenta sus 
condiciones propias como la cultura, los recursos naturales y la infraestructura local.

\section{ELEMENTOS COMPONENTES DE LA GESTIÓN DEL CONOCIMIENTO PARA EL DESARROLLO LOCAL}

Elemento explícito $\circ$ implícito es la incorporación de la dimensión territorial en las propuestas de desarrollo, es considerar que el ámbito de acción de la propuesta va más allá del espacio agrícola. Se debe considerar la heterogeneidad social de los territorios, en el sentido de ir más allá de la focalización de las iniciativas en las familias rurales e incorporar o convocar a los distintos agentes que tienen presencia relevante en el espacio rural. Hay que incorporar empleos agrícolas y no agrícolas como destinatarios de acciones orientadas a incrementar productividad.

Es necesario enfatizar en la articulación entre los sectores agrícola, industrial y de servicios y considerar la agroindustria y el agro-comercio motores potenciales del desarrollo agropecuario local. Elemento derivado de lo anterior es la incorporación de los vínculos urbanorurales en la definición del espacio de acción relevante, en lugar de reducirse solo al espacio agrícola. Crucial en las estrategias es la creciente relevancia que se da al componente institucional del desarrollo agropecuario, a partir del aporte hecho en la década de 1990 por las ciencias sociales. La integración de los conceptos de espacio rural como territorio, de heterogeneidad social de los agentes, de multi-sectorialidad en el empleo, de articulación intersectorial, de incorporación de los vínculos urbano-rurales y de relevamiento de lo institucional, permite intentar una síntesis que recoja los aportes de distintas experiencias, propuestas y teorías y que hemos denominado desarrollo agropecuario.
El autor define desarrollo agropecuario local como proceso de transformación productiva e institucional del espacio rural, cuyo fin es reducir la pobreza rural de forma integral. De la definición se desprende que el desarrollo agropecuario local descansa sobre dos pilares: transformación productiva $y$ desarrollo institucional. La transformación productiva articula competitiva y sustentablemente a la economía del territorio con mercados dinámicos, lo que supone cambios en los patrones de empleo y producción de un espacio rural determinado. El desarrollo institucional tiene como objetivo estimular la concertación de los actores locales entre sí y con agentes externos relevantes y modificar las reglas formales e informales que reproducen la exclusión en los procesos y los beneficios de la transformación productiva.

\section{Entorno rural y gestión agropecuaria local como dimensiones del desarrollo local}

Según Méndez (2005), son objetivos fundamentales del desarrollo territorial satisfacer la necesidad básica del pueblo en servicios e infraestructura, mejorar distribución del fruto del desarrollo y participación económica, social y política, aumentar calidad de vida mejorando asentamientos urbanos y rurales, impulsar crecimiento económico con aumento sostenido de bienes y servicios y ampliación de la capacidad productiva regional, proteger el entorno natural y la obra humana y consolidar la autonomía territorial entendida como creciente autodeterminación política del territorio, identificación de sus habitantes y apropiación del plusproducto económico. Esos mismos criterios se cumplen en el desarrollo agropecuario local 
De Janvry et al. (2003) sostienen que para reducir la pobreza rural es necesario crecimiento y enfoque territorial del desarrollo agropecuario local. Para esto se requieren tres niveles de intervención: primero: intervenir eficientemente en las precondiciones de educación, salud, nutrición e infraestructura; segundo: impulsar el crecimiento regional con un enfoque territorial del crecimiento económico para generar oportunidades locales de ingreso y tercero: ayudar a la incorporación económica de los actores del sector rural, con enfoque territorial del desarrollo agropecuario local.

El autor considera que este planteamiento está permeado aún por modos de actuación e ideología intervencionista al trabajar en comunidades rurales a pesar de las buenas intenciones. Considera a los destinatarios de la "ayuda" como individuos no preparados para desarrollar su comunidad que necesitan de la sapiencia del técnico. Al trabajar con presupuestos intervencionistas no se enseña a los actores a descubrir sus potencialidades y se corre el riesgo, al no crear competencias para el autodesarrollo local comunitario, de emprender proyectos insostenibles.

Lo rural puede generar riquezas si le damos valor agregado a producciones incorporando conocimiento al producto con uso intensivo de la ciencia (know how). Incrementar la productividad y rentabilidad de la producción agropecuaria e industrializar la producción agropecuaria, confecciones básicas y turismo para beneficio de la comunidad, son acciones simples y necesarias que se debe motivar que el poblador rural las inicie de manera globalizada. Se necesita habilitar al actor rural con recursos para disponer de la base para impulsar actividades productivas, rentables y sostenibles en el tiempo. Es necesario organizar y capacitar a la familia rural para gestionar sus actividades con eficiencia y superar problemas de producción, comercialización, precio y distribución.

Según Prato et al. (2003) la estrategia más adecuada y humana para solucionar el problema es priorizar el desarrollo social, obligadamente multisectorial en lo rural. El desarrollo agropecuario hasta hoy es considerado solo agropecuario o artesanal y se orienta casi siempre al incremento productivo. Al campesino se le ve solo como productor y se olvida que sus actividades son formas de vida, tiene una familia, conforma una comunidad, pertenece a un entorno y demanda las facilidades del medio urbano. No se le considera como persona.

La visión tradicional identifica desarrollo rural con desarrollo agropecuario pero este último no puede pensarse aislado del desarrollo urbano porque ambos conforman un conjunto de funciones económicas y sociales relacionadas ya que el medio rural precisa insumos, maquinaria, manufacturas y servicios del medio urbano y el medio rural necesita mercados urbanos para vender sus productos. El medio urbano precisa recursos naturales (agua potable, materias primas) y bienes y servicios (ocio, deporte, naturaleza) que produce el medio rural. Hoy las zonas rurales son valoradas por razones ecológicas de conservar el medio natural y bienes y servicios ambientales. (Alburquerque, 2003)

Hace unos años ocurrieron cambios en las concepciones sobre desarrollo agropecuario. Crece la preocupación por el medio ambiente y la construcción de una estrategia sostenible y competitiva para la agricultura. En el plano social son temas relevantes lograr equidad y participación, desvalorizándose la planificación central como método de promoción del 
desarrollo y siendo reemplazada por una estrategia de sectores sociales y económicos organizados en el ámbito local, con un papel más efectivo en elaborar y ejecutar programas de desarrollo.

Los conceptos y objetivos del desarrollo agropecuario han sufrido cambios tan radicales que las orientaciones de la acción implementadas hoy se llevan a cabo de modo contrario al pasado. Antes el desarrollo era centralizado y hoy es cada vez más descentralizado; había poca preocupación por el medio ambiente y hoy es aspecto central; no se consideraba la participación elemento importante $y$ hoy es medio $y$ objetivo estratégico; las acciones estaban dirigidas al hombre jefe de hogar y hoy se propone el enfoque de género como aspecto central. Igual ocurre con la como tecnología, pedagogía y papel del comercio.

Hoy las políticas de desarrollo rural buscan alcanzar, como objetivo general, sostenibilidad y equidad del desarrollo, propósitos a resumir en el concepto desarrollo sostenible a escala humana. Emplearemos la expresión desarrollo agropecuario solo si este es sostenible, de lo contrario no es desarrollo. La búsqueda de sostenibilidad pretende que los recursos empleados no produzcan agotamiento rápido de recursos naturales. El enfoque de equidad emplea metodologías para que el beneficio llegue a todos $y$ fortalecer posibilidades productivas y de participación social del sector con menos poder de la sociedad rural.

Los objetivos de sostenibilidad y equidad social en el desarrollo implican focalizar recursos para mejorar la calidad y cantidad de producción, garantizar condiciones de vida en el campo $y$ asegurar sostenibilidad para beneficio de futuras generaciones. Buscan fortalecer a las organizaciones sociales con capacidad para incorporarse a la gestión social y política, en el ámbito de la comunidad y otras instancias de poder.

\section{Participación}

Incorpora la idea de tener un papel concreto en la ejecución, seguimiento y evaluación de las acciones de desarrollo. Un proceso de cambio agrícola sostenible no puede imponerse, debe surgir del campesino por medio de mecanismos de participación comunitaria. El desarrollo de la capacidad de participar del campesino se realiza a través de las organizaciones comunitarias, incrementando las posibilidades de alcanzar la autogestión de los proyectos, ya que ésta permite que las acciones a realizar estén en sintonía con los intereses comunitarios.

La promoción de participación tiene tres objetivos principales: compromiso: incorporar la comunidad al proceso de gestión y desarrollo del proyecto, generar compromiso mediante apoyo del esfuerzo colectivo para el mejor desempeño de las acciones implementadas y sostenibilidad de las mismas; capacitación: es educativa en el sentido que los campesinos, al participar de la discusión de los problemas, tienen acceso al conocimiento de tecnologías y procesos productivos y capacidad de decidir cuáles adoptar como elemento central para el éxito del proyecto pues crea y fortalece capacidades que garantizan sostenibilidad del desarrollo al incorporar al imaginario comunitario el Know how para conducir el desarrollo local y eficiencia pues la participación comunitaria es factor que interviene positivamente para mejor utilización de los recursos.

Al sistematizar resultados de un estudio de la Agencia Interamericana de Desarrollo sobre 36 proyectos de desarrollo agropecuario integrado en 
África y 35 en América Latina se comprobó que es muy importante que la población participe en el diseño y generación del proyecto y su implementación. (Tobal, 20I2). La experiencia indica que los proyectos deben elaborarse y ejecutarse compartiendo entre propiciadores y población las decisiones.

\section{Enfoque de género}

Para lograr verdadera participación social se requiere compromiso de todos los componentes de la sociedad, particularmente las mujeres. Para que sea posible se requiere un cambio de mentalidad entre mujeres $y$ hombres. Es necesario que las mujeres tengan conciencia de sus derechos y deberes y se incorporen a la labor junto a los hombres. Por ello el esfuerzo se orienta a generar metodologías y tecnologías que liberen tiempo a la mujer, que con el exceso de tareas que realiza no puede participar masivamente en la sociedad y la economía. Del hombre se requiere aceptar la participación de la mujer bajo nuevas formas y asumir tareas que tradicionalmente fueron de ellas. Hoy el enfoque de género es central en las nuevas estrategias de desarrollo y en la elaboración de los proyectos debe tener también un lugar significativo. El logro de estos cambios de visión y de conducta de las relaciones sociales y de trabajo en mujeres y hombres, con el objetivo de alcanzar mayor equidad social es una de las principales dimensiones a tener presente en la construcción del marco de referencia de todo proyecto de desarrollo sostenible.
Incremento de la productividad

Diversos factores relativos a la producción y comercio generan condiciones adversas para el desarrollo que causan problemas de abastecimiento a la población, industria y mercado externo. En ese contexto, el desarrollo rural sostenible tiene como objetivos elevar la oferta de productos agrícolas, dinamizar la economía y capacitar actores para insertarse al mercado internacional e incrementar ingresos de familias campesinas y sector rural. Mayor dinamismo de la economía permite mejorar el nivel de empleo y las condiciones de vida del campesino en salud y educación.

El objetivo aumentar la producción debe verse como parte del sistema amplio de la cadena produccióncomercialización y para lograrlo hay dos estrategias complementarias o alternativas: aumentar el área cultivada con deforestación o, en sintonía con los imperativos del desarrollo sostenible, dar mayor importancia a la productividad, con mejora en prácticas tecnológicas, métodos de cultivo y nuevas tecnologías. Para lograr los objetivos de cualquier proyecto de desarrollo sostenible se debe preferir la segunda estrategia que aporta elementos para la sostenibilidad de la producción y disminuye presión sobre el medio. Por eso el desafio del desarrollo rural sostenible es elevar la productividad con tecnologías con menor uso de agroquímicos y respeto a los recursos de bosques, suelos y aguas. Para este desafío todavía no hay repuesta clara en el campo tecnológico y la solución vendrá, no de los laboratorios, sino de prácticas concretas de campo en las condiciones reales de cada región. 


\section{Sostenibilidad ambiental}

El nuevo modelo de desarrollo agropecuario no debe reducir el principio de sostenibilidad a iniciativas de protección del suelo y aguas. Debe incorporarlo integralmente en los objetivos y estructura del proyecto, de forma que cada acción contenga elementos de sostenibilidad ambiental entendida como principio sobre el que se estructura todo el proceso de desarrollo agropecuario local. Una forma de incorporar la sostenibilidad ambiental al proyecto de desarrollo agropecuario es promover nuevos cultivos y asociaciones entre éstos para preservar y recuperar áreas degradadas con nuevas técnicas y manejo agroecológico de suelos, plagas y enfermedades. El equipo técnico debe relacionarse con centros de investigación, MINAGRI y CITMA y buscar información de nuevas tecnologías.

El modelo institucional cubano, caracterizado por marcado centralismo, se expresa aún a escala local en lógicas que prolongan la acción de los actores centrales. Las instituciones de Educación Superior deben jugar un papel en diseñar políticas orientadas al desarrollo agropecuario local. Actualmente están llamadas a jugar un papel cada día más activo. Ello requiere que profesores, investigadores, alumnos y directivos sean conscientes de su importante papel en tal ámbito. Ello conlleva a desarrollar su rol de ciudadanos.

El autor de esta investigación considera que estos elementos pueden ser eficientemente tratados si se emplea un modelo de gestión del conocimiento para el desarrollo agropecuario local que los tenga en cuenta como potencialidades u obstáculos.

\section{ROLES DE LA EDUCACIÓN SUPERIOR, REPRESENTADA POR EL CUM, EN EL DESARROLLO LOCAL}

Sería incongruente proponer un modelo de gestión del conocimiento para el desarrollo agropecuario de un municipio cubano sin tener en cuenta el papel que debe jugar la Educación Superior en ese escenario. Las Universidades son conceptualizadas como instituciones llamadas a generar y difundir conocimientos. Deben ser el sitio donde se deposite y a partir del cual se difunda el saber universal, o por lo menos, el medio para acceder a él. Es por eso que la investigación realizada en la Universidad debe ir encaminada a resolver problemas concretos y los proyectos deben surgir basados en necesidades reales a atender. No debemos desperdiciar recursos económicos en investigaciones que no van a trascender y terminarán engavetados. (Hernández et al., 2015)

Con los importantes avances en el campo de las telecomunicaciones, en especial lo referido a la informática, se están conformando amplias e intrincadas redes que enlazan a un sinnúmero de universidades, que deben establecer una estrategia para participar en ellas. Mediante un eje integrador metodológico de investigación - acción interdisciplinaria las TIC se deben involucrar en el diseño y elaboración de las propuestas de Plan de Desarrollo Municipal.

El gobierno puede poner en práctica las líneas de acción esbozadas en unión con el equipo de académicos y aún sin ser sometidas a estricta evaluación se podría decidir que las políticas sugeridas e implementadas entre académicos y actores locales pueden ser muy acertadas. Esa idea de colaboración no cuaja si el grupo presenta fisuras, diferencias irreconciliables, actitudes protagónicas, diferencias en 
los objetivos y metodologías a emplear y las propuestas a realizar; incomprensión de los tomadores de decisiones respecto al trabajo académico en sus contenidos, formas o ritmos e incapacidad para desarrollar la interfase que permita una comunicación más fluida o por incomprensión de los académicos del papel dirigente del gobierno y olvido de su condición de participantes y asumir un protagonismo que no les corresponde.

\section{Papel de la Universidad en el desarrollo agropecuario local}

Ante estas tendencias los integrantes del Grupo de Desarrollo Local deben asumir un papel ciudadano. Esto ayuda a los actores locales a asumir su papel en interés de la comunidad. Los académicos siempre estarán perneados por su carácter de intelectuales y su accionar es influido por su formación intelectual que los lleva en ocasiones a no entender el papel de los tomadores de decisión. El accionar del Grupo de Desarrollo Municipal debe contribuir a recuperar el saber regional, integrando el saber vernáculo y el de las comunidades. Esta recuperación y sistematización del saber de la región y la región como saber, es fuente inagotable de trabajo, elemento constitutivo de pertinencia territorial, del enraizamiento de las poblaciones. Es la historia de la región, pero también un potencial inagotable de recursos para la transformación social. (Hiernaux, 1999).

Con su postura los académicos deben contribuir a que las Universidades se involucren en el diseño e implementación de políticas de desarrollo agropecuario local. En universidades o centros de investigación debe darse un proceso de innovación para encontrar mecanismos más idóneos para estrechar sus lazos con lo local. Esa relación a construir debe tomar en consideración al municipio como sujeto en consideración de que los procesos de globalización lejos de agotar a la región la revitalizan, teniendo que tomar al territorio como base de la misma globalización y que la universidad. Hoy más que nunca, debe asumir que para penetrar en las esferas globales debe articularse con su municipio y provincia, los municipios vecinos y las redes de conocimientos, productivas y políticas que en ellos actúan.

En 2002 se inició en Cuba un proceso de transformaciones de la Educación Superior con el objetivo de garantizar el pleno acceso de toda la población a todas las actividades sustantivas, cultivando su inteligencia y multiplicando gradualmente sus conocimientos. A partir de los recursos materiales y humanos creados durante estos fructíferos años de revolución y que hoy se encuentran diseminados por toda la Isla. (MES, 2004). Para dar respuesta a estas nuevas exigencias surgen los Centros Universitarios Municipales (CUM) y se inicia un amplio programa de Universalización. La nueva universidad, abierta a toda la sociedad, se distingue de la tradicional por trascender sus muros y desarrollar sus procesos en comunidad con el pueblo, perfeccionándose continuamente como parte de una interrelación participativa.

Los CUM, en su primera etapa, se dedicaron a garantizar la continuidad de estudios con la calidad requerida. Hernández et al., (2013) plantea que se incorporaron otros procesos sustantivos de la vida universitaria como respuesta a las necesidades del desarrollo de cada territorio. Estas misiones imponen la necesidad de lograr con urgencia la integración y cooperación de todos los factores del territorio para elevar la calidad, racionalidad y pertinencia de los resultados de nuestras instituciones. Esa es la única 
forma de dar respuesta a las complicadas demandas que plantea el gobierno y las instituciones del territorio.

A tono con las ideas anteriores, el punto de partida para identificar el papel y lugar de la universidad actual, y con ello poder establecer del mejor modo posible su modelo de formación, hay que buscarlo en la misión de la universidad. Según Hourruitinier et al. (2009) esta consiste en preservar, desarrollar y promover, a través de sus procesos sustantivos y en estrecho vínculo con la sociedad, la cultura de la humanidad. La misión asignada a la nueva Universidad cubana en las nuevas condiciones de la municipalización nos conduce a preguntar ¿Cómo lograr la integración de todos los factores del territorio garantizando el desarrollo agropecuario local y el cumplimiento de la misión de la Educación Superior bajo las condiciones del municipio?

La producción de conocimiento a nivel local plantea varios retos. Frecuentemente los problemas son complejos y necesitan abordaje multi o interdisciplinario, requieren integración de varias disciplinas en la búsqueda de respuestas cuya solución se logra muchas veces combinando inteligentemente los conocimientos existentes; generalmente el conocimiento que se requiere está integrado a la práctica, se necesita para resolver un problema y buena parte del mismo existe por lo que solo es necesario transferirlo con creatividad teniendo en cuenta la singularidad de las circunstancias locales y, por último, existe un fuerte nexo entre innovación y aprendizaje por lo que para introducir lo nuevo antes hay que capacitar al personal que trabajará en el proceso. (Núñez et al., 2006)

El primer reto obliga a tener un levantamiento de los profesionales del territorio acompañado de los conocimientos que manejan y en que pueden aportar al enfoque multidisciplinario de la solución de cualquier problema. El segundo reto crea necesidad del aprendizaje por parte de los actores locales de la red para realizar funciones que les corresponden en el contexto de la misma. Esto lleva a la necesidad de un programa de educación continua que engrana con el tercer reto de capacitar y superar a los actores de la red para prepararlos para a enfrentar el nuevo conocimiento generado.

En la gestión del conocimiento a nivel local se deben eliminar distancias que artificialmente se han creado entre disciplinas, actores y procesos de aprendizaje, superación, capacitación, investigación e innovación. Esto obliga a trabajar integradamente a los actores para obtener conocimiento utilizable. Es imprescindible encaminar acciones para optimizar los recursos humanos y dar un trato adecuado y justo a las personas que integran la red. Todo ello requiere una dirección centralizada de esos recursos, que posibilite una proyección prospectiva que favorezca en el tiempo los saltos cualitativos derivados de los saltos cuantitativos. Con ello avanzamos hacia la integración estratégica. (Cloke y Goldmith, 2000)

En el CUM, lograr una dirección eficiente, eficaz e integrada revierte singular importancia, pues lleva aparejado un sinfín de acciones encaminadas sobre concepciones educativas y curriculares asumidas que declaran el carácter nacional, científico, democrático, popular y político en un proceso de vinculación y mutua influencia con la sociedad. Lleva implícito desarrollar investigación científica en la institución, lo que repercute en apoyo intelectual a la teoría de las ciencias y economía productiva y social. Por último, llega a la comunidad en actividades extensionistas. 


\section{CONCLUSIONES}

El modelo que nos articula a la economía mundial no soluciona problemas apremiantes y se expresa en deterioro de ecosistemas, condiciones ambientales y calidad de vida y alcanzar un desarrollo agropecuario local sostenible se enfrenta a un escenario de desigualdad social y disparidad territorial que son restricciones fundamentales para la sostenibilidad social y ambiental de un nuevo modelo que privilegie el desarrollo agropecuario basado en la gestión sostenible del conocimiento.

La Educación Superior debe actuar en el municipio como gestor de conocimiento y la innovación, minimizar las amenazas y potenciar las oportunidades que se presenten para cumplir su función, a partir de las transformaciones en la Educación Superior, con calidad, eficiencia y racionalidad.

Para ser sostenible, un modelo de gestión del conocimiento para el desarrollo agropecuario local debe ser incluyente, equitativo y participativo desde su concepción, en su gestión e implementación lo que requiere fortalecer el capital social mediante la participación que debe estar íntimamente ligada al acceso a la toma de decisiones para ir responsablemente hacia la meta de que todos los actores se conviertan en protagonistas del desarrollo, organizados en diversos niveles de consulta, discusión y toma de decisiones con respecto a estrategias, planes y proyectos, monitoreo y auditoria social.

El esquema de coordinación y concertación para la planificación e implementación participativa del modelo de desarrollo agropecuario local sostenible se basa en las estructuras político-administrativas existentes y promueve la institucionalidad.

\section{REFERENCIAS}

Aguilar, M. Ander-Egg, E. (2006). Diagnóstico social. Conceptos y metodología. Buenos Aires: Editorial Lumen.

Aguilera, L. y Bao, L. (2008). La competencia innovativa para la formación del gestor del desarrollo local basado en gestión del conocimiento y la innovación. Sinnco 2008. Congr. Sist. Innov. para Competitividad. III Ed. Guanajuato, México.

Alarcón, R. (20I2). Desarrollo Local. Conferencia en el Tercer Taller Nacional. Segunda Etapa del Programa Ramal GUCID del MES. (24 de mayo). Hotel Tulipán. La Habana. Carta GUCID No. 8. Julio.

http://www.vriep.uh.cu/ctsuh I/?q=content/public aciones.

Albornoz, M., Alfaraz, C. (2006). Redes del conocimiento: Construcción, dinámica y gestión. Red Iberoam. de Indicadores de Ciencia y Tecn. (RICYT). Buenos Aires, Argentina.

Alburquerque, F. (2003). Teoría y Práctica del Enfoque del Desarrollo local. Consultoría de capacitación en Desarrollo territorial y gestión del territorio, promovida por la Unión Europea en La Serena, región de Coquimbo. 24-30 agosto. Chile.

Alburquerque, F. (2003a). Curso sobre desarrollo local. Inst. Econ. y Geografía. Madrid: Cons. Sup. de Inv. Cient. Consultado el 28 de febrero de 2016 en http://www.ieg.csic.es/cv/docs/FalburquerqueCV\%20extendido.doc

Alonso, J., Pérez-Yera, A., Rivero, R., Romero, E., Riera, C. (Eds.) (20I2). El Autodesarrollo Comunitario. Crítica a las mediaciones sociales recurrentes para la emancipación humana. Centro de Estudios Comunitarios. Universidad Central "Marta Abreu" de Las Villas. Santa Clara: Ed. Feijoó.

Alonso, J. y Riera, C. (20I0). El interventor social no es todopoderoso. Retos epistémicos del desarrollo comunitario. Rev. Complexus (I0).

Arés, P. (2003). Cultura familiar comunitaria vs cultura de mercado en un mundo globalizado ¿Solidaridad o pragmatismo? Jubileo, deuda externa y cotidianidad. (12-23)

Arocena, R y Sutz, J. (2006). El estudio de la Innovación desde el Sur y las perspectivas de un Nuevo Desarrollo. Ciencia, Tecnología, Sociedad e Innovación. 2(7), I-I2 (Sep.-dic.) 
Arroyo, D. (2002). Los ejes centrales del Desarrollo Local en Argentina. Consultado el II de julio de 2015 en http://www.programacea.org/...desarrollo...local/.. .los-ejes-centrales-del-desarrollo-local-enargentina

Bañegil, T., Sanguino, R. (2008). La estrategia basada en el conocimiento y en el ámbito territorial. Revisión teórica. Pensamiento y Gestión. (25), I13.

Bárcenas, A. (20I2). Conferencia dictada en la Universidad de La Habana. Cuba: Periódico Granma (7 feb.)

Becerra, F. (2008). Teorías sobre el desarrollo. Maestría de Ciencia, Tecn. y Soc. Guía de estudio. Univ. de Cienfuegos.

BID. (2000). Estrategia para el desarrollo agroalimentario en América Latina y el Caribe. Washington: BID.

Boffill, S (2010). Modelo general para contribuir al desarrollo local, basado en el conocimiento y la innovación. Caso Yaguajay. Tesis de Doctorado en Ciencia Técnicas. Fac. Ing. Industrial. Univ. de Matanzas.

Boisier, S. (200I). Desarrollo local: ¿De qué estamos hablando? Universidad Central "Marta Abreu" de Las Villas. Santa Clara. Villa Clara. Cuba.

Bordieu, P. (20I I). La esencia del Neoliberalismo. Consultado el 6 de marzo de 2016 en http://aquevedo.wordpress.com/la-esencia-delneoliberalismo-por-pierre-bourdieu/

Bueno, E. (2003). Enfoques principales y tendencias en dirección del conocimiento. en Hernández, $R$. (Ed.) Dirección de Conocimiento: Desarrollo Teórico y aplicaciones. (pp. 2I-54). Trujillo: Ed. Coria.

Carrasco, M.; Hernández, C.; Fernando, S.; Vera-Cruz, A. (20I5). Integration of university projects to local development: Case Study of Camajuaní municipality. Proceedings. GLOBELICs 2015. 23 25 sept. Ciudad de La. Habana.

Carmona, A. y Vásquez, F. (2008). ¿De qué territorio estamos hablando? Consultado el 9 de marzo de 2016 en

http://www.rimisp.org/seminariotrm/doc/CARM ONA.pdf

Casalis, A. (2007). Desarrollo local y equidad.

Consultado 18 marzo de 2016 en

http://www.pais-global.com.ar

Casanova, F. (2009). Desarrollo local, tejidos

productivos y formación. Consultado el 24 de mayo de 2016 en

http://www.ilo.org/public/spanish/region/.../index. $\underline{\mathrm{htm}}$
Casas, R. (2015). Procesos interactivos entre actores, redes de conocimiento, espacios regionales.

Taller de experiencias de vinculación academiasector productivo. 9-12 feb. Univ. San Gerónimo. Habana.

Chiriboga, M. (2002). ¿Qué hemos aprendido del desarrollo agropecuario de los 90s? En: Schejtman, A. y Berdegué, J. (2004). Desarrollo territorial rural. Debates y Temas Rurales No. I. RIMSIP. Centro Lat. Des. Agropec. Santiago, Chile.

CITMA (2002). Bases para la Introducción de la Gestión del Conocimiento en Cuba. La Habana: Ed. Academia.

Cloke, K. y Goldsmith, J. (2000). El fin del management y el surgimiento de la democracia organizacional: Guía práctica para el puesto de trabajo del futuro. Traducido por Portuondo, A. Ciudad de la Habana.

Correa, R. (2009). Conferencia Magistral. (9 enero) Aula Magna. Univ. de La Habana. Ciudad de La Habana.

Cravacuore, D. (20I0). La articulación de actores para el desarrollo local. Consultado el 7 de junio de 2016 en:

http://www.saap.org.ar/esp/docscongresos/congr esossaap/VII/programa/paneles/d/dI/cravacuore.pdf

D’ Angelo, O. 200I. Sociedad y educación para el desarrollo humano. 202 p. La Habana: Public. Acuario.

De Janvry, A., Araujo, C. y Sadoulet, E. (2003). El desarrollo agropecuario con una visión territorial. Consultado el 14 de diciembre de 2015 en http://www.amer.unam.mx/docs/Janvry.pdf_2003.

Díaz, M. y Arroyo, M. (2006). La Gestión de información para la gestión del conocimiento en la innovación del desarrollo local: Caso práctico de la Universidad de Pinar del Río. En La Nueva Universidad Cubana y su contribución a la universalización del conocimiento. La Habana: Editorial Félix Varela.

Dirven, M. (1998). Agroindustria y pequeña agricultura: Síntesis comparativa de experiencias. LC/R I663. CEPAL.

Fajardo, L., Figueiras, D. (2009). Acercamiento a los procesos de integración en el desarrollo territorial y local. Departamentos de Sociología y Marxismo y Centro de Estudios Comunitarios. Facultad de Ciencias Sociales. Universidad Central Marta Abreu de las Villas. Santa Clara: Editorial Feijóo. 
Faloh, R. (2009). Gestión del conocimiento: Enfoque gerencial.

FAO (2004). La agricultura orgánica, ambiente y seguridad alimentaria. Dpto. Des. Sostenible: Documentos de la FAO.

Ferreira, L. (2009). ¿La intensidad de la relación entre los actores en una red innovativa es posible de evaluarse? Universidade Federal do Rio de Janeiro.

FIDA (2002). Dar a los campesinos pobres oportunidad de salir de la pobreza. Marco estratégico FIDA 200206. Roma.

Garcés, R. (2008). La identidad remediana y la cultura de la resistencia y el período especial.

Consultado el 17 de diciembre de 2016 en http://pr.indymedia.org/news/2008/09/33536.php

Garcés, R. (2013). La gestión del conocimiento en las condiciones del municipio de Remedios como contribución a su desarrollo local. Tesis Doctoral en Ciencias Sociológicas. Santa Clara: Centro de Estudios Comunitarios. Fac. C. Sociales. Universidad Central "Marta Abreu” de Las Villas.

García, J. (2010). CUM. Gestores de Conocimiento y la Innovación. Amenazas y Oportunidades a partir de la Calidad y Pertinencia. I Taller de Segunda Etapa del PR GUCID. 27-29 oct. ICA - San José: MES.

García, J., Fernández, A., González, M. (2016). Impacto de la Educación Superior Cubana en el desarrollo de Sistemas de Innovación Local. Ponencia. Comisión V. Universidad, Ciencia y Tecnología. X Congreso Internacional Universidad 2016. C. de La Habana: Palacio de Convenciones.

Guzón, A. (2006). (Comp.) Desarrollo local en Cuba. Retos y perspectivas. La Habana: Editorial Academia.

Hernández, C., Cala, B., Alpízar, E. (2013). Vínculo de la universidad con su entorno social: Estudio de caso Relación del Centro Universitario Municipal con el entorno socioeconómico en Camajuaní, Cuba. ISBN: 978-3-8454-9997-0. Leipzig. Alemania: Ed. LAP LAMBERT Academic Publishing. 218 p.

Hernández, C. (2015). Utilización del trabajo por proyectos para incentivar la innovación tecnológica en los estudiantes universitarios. RECYT. 17(23), 4 - 12.

Hernández, C. y Cárdenas, E. (20I5). Sistema de acciones para mejorar la cultura ambiental y la calidad de vida de la comunidad suburbana de Arroyo Frío, Camajuaní, Cuba. Revista Científica MONFRAGÜE Desarrollo Resilente. 4(2), I33-I 53. ISSN 2340-5457.
Hernández, C. y Carrasco, M. (2015). Integración de proyectos agropecuarios al desarrollo local. Caso de estudio del Centro Universitario Municipal Camajuaní. GUCID. 5(54), I-I I. Febrero.

Hernández, C., Carrasco, M., Garcés, R. (2015). Collaborations and links of Municipal University Centre Local Networks of Knowledge and Innovation: Case Study of Camajuaní, Cuba. Proceedings. GLOBELICs. 23-25 set. C. Habana.

Hiernaux, N. (1999). Los senderos del cambio. Social, tecnológico y territorio en albores del siglo XXI. México: Plaza y Valdés.

Horrutinier, P ; Hernández, P y Sánchez, M. (2009). La universalización de la educación superior. Rev. de la Soc. Cultural José Martí. (10), 8-19.

Iñiguez, L. (20I2). El territorio y lo local en la nueva política económica y social. En: Vidal, P. y Pérez (20I2) Miradas a la economía cubana. El proceso de actualización. C. Habana: Ed. C. Sociales.

Lage, A. (2006). La economía del conocimiento y el socialismo (II): reflexiones a partir del proyecto de desarrollo territorial de Yaguajay. Panel 2. La Habana: Documentos a debate. Los marcos conceptuales del Programa Ramal: en busca de consensos. (PP. 4-22). I Seminario Nacional Programa Ramal GUCID. MES.

Lage, A. (20I0). Intervención en el Tercer Taller de Desarrollo local. Yaguajay. Febrero. Cuba.

Lage, A. (20I I). Conferencia. Taller Nacional del Programa Ramal GUCID. 18-20 de mayo. Yaguajay. Cuba.

Leal, E. (20I I). Conferencia dictada en el Teatro Villena de Remedios. Remedios. Villa Clara. Cuba.

Leff, E. (2006). Complejidad, racionalidad ambiental y diálogo de saberes. Consultado el I 4 de junio de 2015 en

http://www.mma.es/portal/secciones/formacion educacion/reflexiones/2060 l eleff.pdf

Limia, M. (2004). Conferencia. Taller internacional de desarrollo local en municipios de ecosistemas frágiles. 22 sept. Santiago.

Limia, M. (2004b). Construcción del poder desde abajo. Rev. Ciencia, Innovación y Desarrollo. 9(2), 52-57.

Lloret, M., Méndez, E. (2005). Desarrollo Territorial y Local en Cuba. pp. 29. Univ. Central "Marta Abreu" de Las Villas. Santa Clara. Villa Clara. Cuba: Dpto. de Economía.

López, B. (2005). El desarrollo municipal. Su sustento social, jurídico y técnico. Rev. IIESCA. (I). 
Martínez, A. (2009). Gestión del Conocimiento: Conceptos, herramientas y aplicaciones. Consultado el 7 de enero de 2016: http://www.hosting.globalcorporativa.com/mono grafias/monografía I57.pdf

Méndez, E. (2005). Desarrollo territorial y local en Cuba. Santa Clara: Fac. Econ. Univ. C. de Las Villas.

MES. (2004). La Universidad que queremos. Ciudad de La Habana: Oficina del Viceministro Primero.

MES. (20I2a). Informe del Grupo de Expertos No.I. Producción de Indicadores de desarrollo local. Taller Nacional "Formación y medición para la GUCID". La Habana: Programa Ramal GUCID.

MES. (20I2b). Informe del Grupo de Expertos No. 2. Indicadores para la GUCID. Taller Nacional "Formación y medición para la GUCID". La Habana: Programa Ramal GUCID.

Nonaka, I., Takeuchi, H. (1999). La organización creadora de conocimiento. Cómo las compañías japonesas crean la dinámica de la innovación. Consultado el 3 de enero de 2016 en http://www.monografias.com/trabajos / 3/laorgcre llaorgcre.shtml\#top

Núñez, J., Montalvo, L., Pérez, I. (2006). Gestión del conocimiento, la ciencia, tecnología e innovación en la NUC: aproximación conceptual. En: $L a$ NUC y su contribución a la universalización del conocimiento. C. Habana: Ed. Félix Varela.

Núñez, J., Benítez, F., Hernández, D., Fernández, A. (2008) Universal higher education and sustainable social development: The Cuban model. The International Journal of Cuban Studies. I (I), 23-32.

Núñez, J. (20I0). Educación Superior y desarrollo local: la agenda emergente y sus demandas conceptuales. Boletín GUCID. I(I), 3-9.

Núñez, J. (20I I). Conocimiento académico y sociedad. Ensayos sobre política universitaria de investigación y posgrado. La Habana: Editorial $\mathrm{UH}$.

OEl. (20I2). Ciencia, tecnología e innovación para el desarrollo y la cohesión social. Programa iberoamericano en la década de los bicentenarios. Madrid: OEI.

PCC (20I I). Lineamientos de la política económica y social del Partido. VI Congreso. Ciudad Habana. Ed. Política.

Pereira, H. (20I I). Implementación de la Gestión del Conocimiento en la empresa. CEGESTI. (I35).
Pérez, A. (20I I). Desarrollo local: Estudio sobre las condiciones del gobierno para generar desarrollo local en el municipio de Manicaragua, provincia de Villa Clara. Tesis Doctoral. Santa Clara: Centro de Estudios Comunitarios. Facultad C. Sociales. Univ. Central "Marta Abreu" de Las Villas.

Prada, R. (20/2). Gestión del conocimiento vs. gestión de las habilidades creativas en las organizaciones. Boletín Virtual REDIPE. (809).

Prato, C., Müller, E y Castillo, E. (2003). Autoempleo rural: un camino aun por transitar. Lima: Programa Latinoamericano de Desarrollo local y Combate a la Pobreza.

Prieto, A. (20I0). Conferencia. Cong. Internac. Universidad 2010. Palacio de las Convenciones. La Habana.

PROLOCAL (2002). Proyecto de Desarrollo local Sostenible. World Bank Projects. Consultado el 9 de julio de 2016 en http://www.worldbank.org/sprojects/Project.asp? pid=P039437

Reyes, R. (20I I). Modelo de gestión del conocimiento y la innovación para el desarrollo local. Experiencia de la Filial Universitaria Municipal de Yaguajay. Tesis doctoral en C. de la Educación. C. Habana: CEPES. Univ. Habana.

Ritzer, G. (2007). Teoría sociológica clásica. La Habana: Editorial Félix Varela.

Rivero, R., Alonso, J., Riera, C., Pérez-Yera, A. (2008). Hacia una concepción integrada sobre el desarrollo: Sus proyecciones en Villa Clara. Santa Clara: Ed. Feijoó. Univ. C. "Marta Abreu" de Las Villas.

Rodríguez, M. (2005) La gestión del conocimiento, poderosa fuente de ventaja competitiva. Folletos Gerenciales. Junio.

Ruiz, A. (2002). El concepto de territorialidad propuesto en la Ley de Desarrollo Agropecuario Sustentable. Seminario Internacional Enfoque Territorial del Desarrollo agropecuario. Octubre. Veracruz, México: SAGARPA e IICA.

Sábato, J. y Botana, N. (1975). La ciencia y la tecnología en el desarrollo de América Latina, América Latina, ciencia y tecnología en el desarrollo de la sociedad. Chile: Editorial Universidad.

Schejtman, A. (1998). Alcances sobre la articulación rural urbana y el cambio institucional. Memorias. Seminario Interrelación Rural-Urbana y Desarrollo descentralizado. Políticas Agrícolas. (Especial), 139166. Taxco. México. Abril. 
Schulze, A. (2003). Knowledge management in innovation processes. En: Zedtwitz., M. (2003). (Ed.) Management of Technology: Growth through Business Innovation and Entrepreneurship, Selected Papers from the Tenth International Conference on Management of Technology. (Pp. 265-280).

Netherlands: Ed. Pergamon.

Segarra, M. (2006). Estudio de la naturaleza estratégica del conocimiento y las capacidades de gestión del conocimiento: Aplicación a empresas innovadoras de base tecnológica. Tesis Doctoral. Universitat Jaume I. Castellón. España.

Subirats, J. (2005). ¿Es el territorio urbano una variable significativa en los procesos de exclusión e inclusión social? Ponencia. X Cong. Internac. del CLAD sobre la Reforma del Estado y de la Administración Pública. (octubre). Santiago de Chile: Biblioteca Virtual TOP.

Tobal, C. (20I2). Guía para la formulación y evaluación nacional de proyectos de desarrollo agropecuario integrado. Washington, D.C.: OEA.

Veiga, J. (200I) Brasil Rural precisa de uma Estratégia de Desenvolvimento. Série Textos para Discussão (I). Convenio FIPE-IICA (MDA-CNDRS/NEAD). Agosto. http://www.cndrs.org.br/pndrs.asp

World Bank. (2002). Reaching the rural poor. Corporate rural strategy of the World Bank. Washington D.C.: World Bank. 